\title{
Bovine Mx1 enables resistance against foot-and-mouth disease virus in naturally susceptible cells by inhibiting the replication of viral RNA
}

\author{
H.-M. WANG ${ }^{1,2}$, X.-Z. XIA ${ }^{1,3^{*}}$, G.-X. HU ${ }^{1 *}$, L. YU ${ }^{4}$, H.-B. HE ${ }^{1,2^{*}}$
}

\begin{abstract}
${ }^{1}$ College of Animal Science and Technology, Jilin Agricultural University, Changchun, P. R. China, 130118; ${ }^{2}$ Dairy Cattle Research Center, Shandong Academy of Agricultural Sciences, Jinan, P. R. China, 250100; ${ }^{3}$ Key Laboratory of Jilin Province for Zoonosis Prevention and Control, Institute of Military Veterinary Academy of Military Medical Sciences, Changchun, P. R. China, 130122; ${ }^{4}$ Division of Livestock Infectious Diseases, State Key Laboratory of Veterinary Biotechnology, Harbin Veterinary Research Institute, Harbin, P. R. China, 150001
\end{abstract}

Received March 24, 2015; accepted February 19, 2016

\begin{abstract}
Summary. - Innate immunity, especially the anti-viral genes, exerts an important barrier function in preventing viral infections. Myxovirus-resistant (Mx) gene take an anti-viral role, whereas its effects on foot-andmouth disease virus (FMDV) in naturally susceptible cells are still unclear. The bovine primary fetal tracheal epithelial cell line BPTE-siMx1, in which bovine Mx1 gene was silenced, was established and treated with IFN alpha for $6 \mathrm{hr}$ before FMDV infection. The copy numbers of the negative and positive strand viral RNA were determined by strand-specific real-time fluorescence quantitative RT-PCR. The TCID ${ }_{50}$ of BPTE-siMx1 cells increased at least 17 -fold as compared to control cells BPTE-LacZ at $8 \mathrm{hr}$ post infection, thus silencing of bovine Mx1 could promote the replication of FMDV. The amount of both the negative and positive strand viral RNA in BPTE-siMx1 cells significantly increased as compared to BPTE-LacZ cells, indicating that the replication levels of viral RNA were promoted by silencing bovine Mx1. The bovine Mx1 gene could provide resistance against FMDV in the bovine primary fetal tracheal epithelial cells via suppressing the replication of viral RNA.
\end{abstract}

Keywords: bovine Mx1 gene; foot-and-mouth disease virus; bovine primary fetal tracheal epithelial cell; anti-viral effects

\section{Introduction}

Innate immunity, especially the anti-viral genes, exerts an important barrier function in preventing virus infections (Verhelst et al.,2013). After invading host cells, viruses can induce the generation of interferon (IFN). Interferons type I (IFN-I) and III (IFN-III) play an important role in innate immunity against viral infections. IFN-I, including

${ }^{1 *}$ Corresponding authors: E-mail: xiaxianzhu@gmail.com, huguixue901103@163.com, hongbinh@hotmail.com; phone: 0086431-8698-5516, 0086-431-8453-3482, 0086-531-88679268

Abbreviations: FMD $=$ foot-and-mouth disease; FMDV $=$ FMDvirus; IFN = interferon; $\mathrm{Mx}=$ myxovirus-resistant; OIE = Office International des Epizooties; RNP = ribonucleoprotein; ssqRT$\mathrm{PCR}=$ strand-specific real-time fluorescence quantitative RT-PCR; $\mathrm{TCID}_{50}=50 \%$ tissue culture infective dose
IFN- $\alpha$, can be induced directly in response to viral infection and trigger different processes including the expression of myxovirus-resistant (Mx) proteins (Song et al., 2013). Mx protein is a member of GTPase dynamin superfamily, it can closely interact with ribonucleoprotein (RNP) complex and thus change the configuration of $\mathrm{Mx}$, which in turn activates its GTPase activity to inhibit the reproduction of the virus by interfering with RNA replication, viral protein synthesis, or transfer of the newly synthesized viral proteins, and thus finally exert anti-viral effects (Haller et al., 2011). Previous studies have shown that Mx has a broadspectum anti-viral effects, it can inhibit the replication of RNA viruses and DNA viruses, including Orthmyxoviruses, Togaviruses, Paramyxoviruses, Rhabdoviruses and Bunyaviruses (Stertz et al., 2007; Fernández-Trujillo et al., 2013; Mitchell et al., 2013; He et al., 2014; Hoenen et al., 2014; Patzina et al., 2014). 
Foot-and-mouth disease (FMD) is on the list of infectious diseases of animals of the Office International des Epizooties (OIE) and has been recognized as the most important constraint to international trade in animals and animal product (Leforban et al., 1999). FMD is a highly contagious and economically important agent of cloven-hoofed animals, affecting cattle, swine, and sheep, as well as a large number of wildlife species (Dotzauer and Kraemer, 2012). Outbreaks of FMD have occurred in every livestock-containing region of the world with the exception of New Zealand (Dias et al., 2012; Jamal and Belsham, 2013). The etiological agent of FMD is foot-and-mouth disease virus (FMDV), which is the type species of the Aphthovirus genus of the Picornaviridae family (Domingo et al., 2003). One study revealed that the overexpression of bovine Mx1 protein enabled resistance against FMDV in BHK-21 cells via inhibiting expression of viral proteins (Cai et al., 2013). However, BHK-21 cells are not naturally susceptible for FMDV, and overexpression of bovine Mx1 in vitro, but not under normal physiological conditions, could easily induce artificial effects. As FMDV presumably replicates via a negative-strand RNA intermediate, specific detection of negative-strand RNA level is important to prove active viral replication (Belsham, 2005).

In the present study, the bovine primary fetal tracheal epithelial cells, which are sensitive to FMDV, were used as a naturally susceptible host cell model. Comparison of viral replication in bovine primary fetal tracheal epithelial cells normally expressing Mx1 and in cells with silenced Mx1 expression confirmed that $\mathrm{Mx} 1$ could inhibit viral replication. In addition, silencing of bovine $\mathrm{Mx} 1$ significantly increased the synthesis of positive and negative strand of viral RNA. As expected, overexpressing bovine $\mathrm{Mxl}$ gene inhibited the synthesis of viral RNA in BHK-21 cells. Therefore, bovine Mx1 could exert anti-FMDV effects via interfering with the replication of the viral RNA.

\section{Materials and Methods}

Unless otherwise noted, all reagents used were obtained from Sigma Chemical Co. (USA). All procedures were approved by the Shandong Academy of Agricultural Sciences Animal Care and Use Committee.

Cells. Tracheal tissue was obtained from a fetal Holstein cow of the age of 4 months gestation under aseptic conditions (Wang et al., 2012). The bovine fetal primary tracheal epithelial cells were separated, cultured, and cryopreserved according to the methods described by Hauser et al. (2013). 293T cells and BHK-21 cells were obtained from the American Type Culture Collection and grown in Dulbecco's modified Eagle's medium (DMEM) supplemented with $10 \%$ fetal bovine serum (FBS). The bovine fetal primary tracheal epithelial cells and $293 \mathrm{~T}$ cells were cultured at $37^{\circ} \mathrm{C}$ in a humidified atmosphere of $5 \% \mathrm{CO}_{2}$ in air for several days.
Titration of FMDV. The bovine fetal primary tracheal epithelial cell were passaged in 24-well plates with DMEM medium of $10 \%$ FBS, and infected with 10-fold dilutions of FMDV strain ASIA1/YS/ $\mathrm{CHA} / 05$ in four replicates per dilution when they developed a confluent monolayer. After $48 \mathrm{hr}$, viral cytopathic effect was monitored and $50 \%$ tissue culture infective dose $\left(\mathrm{TCID}_{50}\right)$ of virus was calculated using the Reed-Muench method (Reed and Muench, 1938).

Construction of recombinant lentivirus vectors expressing shRNA targeting bovine Mx1. Lentivirus-based shRNA vectors were constructed as described previously (Wang et al., 2012). The sequences of these of shRNA oligonucleotides are RNAi-Mx1A1: 5'-GCAACCTGTACAGCCAATATGTTCAAGAGACATAT TGGCTGTACAGGTTGCTTTTTTGT-3' and RNAi-Mx1-A2: 5 ' - CTAGACA A A A A A GC A A C C TG TA CA G C CA ATA TGTCTCTTGAACATATTGGCTGTACAGGTTGC-3'; RNAiMx1-B1: 5'-GGAATGAAGACGAGTGGAAAGTTCAAG AGACTTTCCACTCGTCTTCATTCCTTTTTTGT-3' and RNAi-Mx 1-B2: 5'-CTAGACAAAAAAGGAATGAAGA CGAGTGGATCTCTTGAACTTTCCACTCGTCTTCATTCC-3'; RNAi-Mx1-C1: 5'-GGATCAGTCATGAGCTGATTATCAAG AGATAATCAGCTCATGACTGATCCTTTTTTGT-3' and RNAiMx1-C2: 5'-CTAGACAAAAAAGGATCAGTCATGAGCTGA TTATCTCTTGAATAATCAGCTCATGACTGATCC-3'. The control shRNA sequences are LacZ-P1: 5'-CAGTTGC GCAGCCTGAATGTTCAAGAGACATTCAGGCTGCGCAAC TGTTTTTTGT-3' and LacZ-P2: 5'-CTAGACAAAAAACAG TTGCGCAGCCTGAATGTCTCTTGAACATTCAGGCTGC GCAACTG-3'. These oligo-nucleotides were annealed to each other and ligated into $\mathrm{H} 1$ lentivirus vector, followed by DNA sequence confirmation. The sequence of LacZ shRNA was not homologous to those of viral genes, so shRNA of LacZ recombinant lentivirus was negative shRNA control. The PCR primer pair was LT1: 5'-TGTCGCTATGTGTTCTGGGA-3' and LT2: 5'-GGTACAG TGCAGGGGAAAGA-3'.

Construction of recombinant pcDNA3.1 vector expressing bovine $M x 1$. Total RNA was extracted from IFN- $a$-stimulated $(1000 \mathrm{U} / \mathrm{ml})$ bovine fetal primary tracheal epithelial cells with TRIzol reagent according to the manufacturer's instructions and was reverse transcribed using the SuperScript III First-Strand Synthesis System (Invitrogen, USA). The two specific oligonucleotide primers were designed according to the sequence of bovine Mxl (GenBank: NM_173940.2). The sequence of forward primer Mx1-P1 was 5'-CCGCTCGAGGCCACCATGGATTACAAGGATGACGA CGATAAGGTTCATTCTGACTTG-3'. The italics, shadow and underline were indicated $\mathrm{XhoI}$ endonuclease restriction cleavage site, Kozak sequence and Flag-tag sequence in the Mx1-P1 primer, respectively. The sequence of reverse primer $\mathrm{Mx1}$-P2 was 5'-CGCGGATCCTCAGCCCGGGAACTTGGCCA-3'. The italics was indicated $\mathrm{Bam} \mathrm{HI}$ endonuclease restriction cleavage site in the Mx1-P2 primer. PCR was performed at $94^{\circ} \mathrm{C}$ for $5 \mathrm{~min}$, followed by 30 cycles of $94^{\circ} \mathrm{C}$ for $30 \mathrm{sec}, 62^{\circ} \mathrm{C}$ for $30 \mathrm{sec}, 72^{\circ} \mathrm{C}$ for $120 \mathrm{sec}$, and finally $68^{\circ} \mathrm{C}$ for $10 \mathrm{~min}$ (PE-9700 thermocycler). PCR fragments were digested with XhoI and BamHI, and cloned into previously 
digested pcDNA3.1, followed by DNA sequence confirmation. The recombinant pcDNA3.1 vector expressing bovine $\mathrm{Mx} 1$ was named pcDNA3.1-Flag-Mx1.

Co-transfection of lentiviral shRNAs and Flag-tagged bovine Mx1 gene in $293 \mathrm{~T}$ cells. $5 \mu \mathrm{g}$ aliquot of pcDNA3.1-Flag-Mx1 was co-transfected into $293 \mathrm{~T}$ cells with $5 \mu \mathrm{g}$ of relevant recombinant shRNA lentivirus vector, such as RNAi-Mx1-A, RNAi-Mx1-B, RNAi-Mx1-C or RNAi-LacZ, respectively, using Lipofectamine 2000 according to manufacturer's instruction (Invitrogen, USA). After $48 \mathrm{hr}$, transient expression of the Flag-Mxl fusion protein was determined by Western Blot, performed as described by He et al. (2007). In brief, $293 \mathrm{~T}$ cells were lysed in $20 \mathrm{mmol} / \mathrm{l}$ Tris- $\mathrm{HCl}$, pH 8.0, $150 \mathrm{mmol} / \mathrm{l} \mathrm{NaCl}, 1 \%$ Triton, $5 \mathrm{mmol} / \mathrm{l} \mathrm{EGTA,} 5 \mathrm{mmol} / \mathrm{l}$ EDTA, $1 \mathrm{mmol} / \mathrm{l} \mathrm{NaF}, 1 \mathrm{mmol} / 1 \mathrm{Na}_{3} \mathrm{VO}_{4}$, freshly added proteinase inhibitor tablet, and supernatants were collected by centrifugation. Proteins were separated SDS-PAGE and transferred to nitrocellulose membranes. The membranes were probed with antibodies against Flag and $\beta$-actin. Specific proteins were visualized by ECL (Amersham Biosciences, USA) detection. Viral gene expression was quantified relative to the LacZ shRNA control.

Establishment of primary bovine fetal tracheal epithelial cell line with shRNA silencing bovine Mx1. Five $\mu \mathrm{g}$ of recombinant shRNA lentivirus vector RNAi-Mx1-A or RNAi-LacZ was transfected into the bovine fetal primary tracheal epithelial cells using Lipofectamine 2000 (Invitrogen, USA). The cells were subcultured after $48 \mathrm{hr}$, and stable cell lines with shRNAs were screened by FACS analysis based on shRNA recombinant $\mathrm{H} 1$ lentivirus encoding eGFP.

Expression of Mx1 in bovine fetal primary tracheal epithelial cells silencing bovine Mx1 (named BPTE-siMx1) was confirmed by Western blot. The control cell line was named BPTE-LacZ. The stable cell lines BPTE-siMx1 and BPTE-LacZ were cryopreserved in 10\% DMSO and $20 \%$ fetal bovine sera and stored in liquid nitrogen vapor.

FMDV infection. The primary bovine fetal tracheal epithelial cells with silenced Mx1 BPTE-siMx1 and control cell BPTE-LacZ were passaged and cultured in a 24-well culture plate overnight and stimulated by IFN- $\alpha$ in a medium containing 10 -fold dilution of IFN- $\alpha$ the final concentrations of $1 \times 10^{0}-1 \times 10^{5} \mathrm{IU} / \mathrm{ml}$ to induce the cells for 2,4 , 6 , and $8 \mathrm{hr}$, respectively. The total RNA was extracted from the cells with TRIzol reagent (Invitrogen, USA), and the cDNA was prepared with SuperScript III First-Strand Synthesis System (Invitrogen, USA) from the total RNA using oligo dT primer. The cDNA then was subjected to real-time RT-PCR analysis according to the instructions of the manufacturer of QuantiTect SYBR green RT-PCR kit (Qiagen). Cycling program was set as following: $95^{\circ} \mathrm{C}$ for $10 \mathrm{~min}$ for the PCR initial activation and 40 cycles of denaturation at $95^{\circ} \mathrm{C}$ for $15 \mathrm{sec}$, annealing and extension at $60^{\circ} \mathrm{C}$ for $1 \mathrm{~min}$. PCR primer pairs were used as follows: Mx1-P1:5'-ATAAGGTTCATTCTGACTTG-3' and Mx1-P2: 5'-GCCGCACCTTCTCTTCAT-3' for bovine Mx1 RNA, $\beta$-actin-P1: 5'-AGCAAGCAGGAGTACGATGAG-3' and $\beta$-actin-P2: 5'-TGCCAATCTCATCTCGTTTTC-3' for $\beta$-actin. As a control, 10fold dilutions of $10^{7}$ copies of pcDNA3.1-Flag-Mx1 vector and T-actin vector (Wang et al., 2012), respectively, were used. All further computations were done using ABI Prism 7000 SDS Software (Applied
Biosystems). The statistical analysis was based on data from three independent experiments. The ratio of the expression of $\mathrm{Mx} 1 / \beta$-actin in the $10^{1}$ group was considered as 1 , and then the optimal time and dose for IFN- $\alpha$ induction was determined.

BPTE-siMx1 or BPTE-LacZ cells were seeded into 24-well culture plate. When the cells reached $90 \%$ confluence, the cells were induced with $\alpha$-IFN at the optimal dose and time and subsequently infected with the FMDV strain ASIA1/YS/CHA/05 at a multiplicity of infection of $1000 \mathrm{TCID}_{50}$ per well. After the adsorption for $1 \mathrm{hr}$ at $37^{\circ} \mathrm{C}$, cells were washed for $1 \mathrm{~min}$ with $0.1 \mathrm{~mol} / \mathrm{l}$ phosphate buffer ( $\mathrm{pH}$ 6.0) to inactivate unabsorbed virions. The infection was allowed to proceed in MEM supplemented with $2 \%$ FBS. The virus samples were collected every $8 \mathrm{hr}$ from $0 \mathrm{hr}$ post infection at designated time points and frozen at $-80^{\circ} \mathrm{C}$ until the assessment of FMDV titer and viral genomic RNA positive and negative strands.

Generation of RNA standards representing positive and negative strands of genomic RNA. The viral RNA was isolated from FMDV with TRIzol reagent (Invitrogen, USA), the BPTE-LacZ RNA served as control RNA. cDNA was subsequently prepared using random primers in SuperScript III First-Strand Synthesis System (Invitrogen, USA). The standards representing positive and negative strands of genomic RNA were synthesized. The DNA representing both RNAs of FMDV were PCR-amplified using specific primers with the forward primer containing a T7 promoter sequence (TAATACGACTCACTATAG) at the 5 ' end. The sequences of these strand-specific amplification primers were Gneg-F: 5'-GCGTA ATACGACTCACTATAGAGCTTTTTAAA CCGGGCAC-3'; Gneg-R: 5'-CGTTGCACTCCACACTTAC-3'; Gpos-F: 5'-GCGTAATACGACTCACTATAGCGTTGCCTCCACAC TTAC-3'; Gpos-R: 5'-AGCTTTTTAAACCGGGCAC-3'. The PCR products were purified by using the QIAquick PCR purification kit (Qiagen, Netherlands). Purified PCR products were transcribed in vitro using the RiboMAX Large Scale RNA Production System-T7 (Promega, USA) at $37^{\circ} \mathrm{C}$ for $4 \mathrm{hr}$. DNase I (Promega, USA) digestions of the DNA template were performed at $37^{\circ} \mathrm{C}$ for $15 \mathrm{~min}$. The RNA transcript was purified with the RNeasy Mini kit (Qiagen, Netherlands). Concentrations of purified RNA transcripts were determined by spectrophotometry. The molecular copies of synthetic RNA were calculated from the total molecular weight of the segment and the concentration of each RNA strand was adjusted to values equivalent to $10^{9}$ copies per $\mu \mathrm{l}$, and stored at $-20^{\circ} \mathrm{C}$ until further use.

cDNA synthesis and ssqRT-PCR. A series of pre-determined copies of standard RNA or $100 \mathrm{ng}$ of total RNA from each time point of infection were used for reverse transcription using Superscript-III enzyme (Invitrogen, USA). The tagged reverse transcription primer (RT-primer) contained a non-viral tag sequence attached at the $5^{\prime}$ end of the strand-specific viral sequence. Tagged RT-primers for viral positive and negative RNA strands were as follows: ssqPCR(-)-P1: 5 ' - T TCCGAT TAGAGG CGATACGCGTGACCGGT TA TTACTCTT AC-3' for negative strands; ssqPCR(+)-P1: 5'-GACCT GGATAGGCTGTGTGATAAGGCG GGCTTCGTGTGA-3' for positive strands. The RT reaction contained, $5 \times$ buffer, $20 \mathrm{mmol} / \mathrm{l} \mathrm{DTT}$, $0.5 \mathrm{mmol} / \mathrm{l} \mathrm{dNTPs}, 100 \mathrm{nmol} / \mathrm{l}$ RT-primer and $2 \mathrm{U}$ of SuperScript III enzyme in a volume of $20 \mu \mathrm{l}$. The reaction was carried out at $55^{\circ} \mathrm{C}$ for 
$30 \mathrm{~min}$, stopped by heating at $90^{\circ} \mathrm{C}$ for $5 \mathrm{~min}$ and then diluted to 200 $\mu \mathrm{l}(1: 10)$ with nuclease-free water. A previously described method was used to generate $\mathrm{CDNA}$ for the purpose of qPCR using non-tagged primers (Vashist et al., 2012). Next, cDNA was subjected to real-time RT-PCR analysis according to the manufacturer's instruction of QuantiTect SYBR green RT-PCR kit (Qiagen, Netherlands). Cycling program was set as following: $95^{\circ} \mathrm{C}$ for $10 \mathrm{~min}$ for the initial PCR activation and 40 cycles of denaturation at $95^{\circ} \mathrm{C}$ for $15 \mathrm{sec}$, annealing and extension at $60^{\circ} \mathrm{C}$ for $1 \mathrm{~min}$. PCR primer pairs were used as follows: ssqPCR(-)-P2: 5'-TTCCGATTAGAGGCGATA-3' and ssqPCR(-)P3: 5'-AGGCGGGCTTCGTGTGA-3' for negative viral RNA strand; ssqPCR(+)-P2: 5'-GACCTGGATAGGCTGTGTGATA-3' and ssqPCR(+)-P3: 5'-CGCGTGACCGGTTATTACTCTTAC-3' for positive viral RNA strand. The standard curve was generated using in vitro transcribed RNA representing each strand, serially diluted from $10^{7}$ to $10^{1}$ copies per $\mu$. The viral genome copy numbers were determined by interpolation of the standard curve for the respective strand of RNA. Each sample and standard curve was run in triplicate to ensure reproducibility. All further computations were done using ABI Prism 7000 SDS Software (Applied Biosystems).

\section{Results}

Establishment of bovine fetal primary tracheal epithelial cell line with silenced bovine Mx1

We generated three lentiviral shRNAs targeting bovine Mx1 as follows: RNAi-Mx1-A, RNAi-Mx1-B, RNAiMx1-C, and co-transfected each individual construct with pcDNA3.1-Flag-Mx1 into 293T cells. Expression of Flag-Mx1 was determined by Western blot. The shRNAs against bovine Mx1 significantly inhibited transient expression of Flag-Mxl as compared to the LacZ-control shRNA (a)
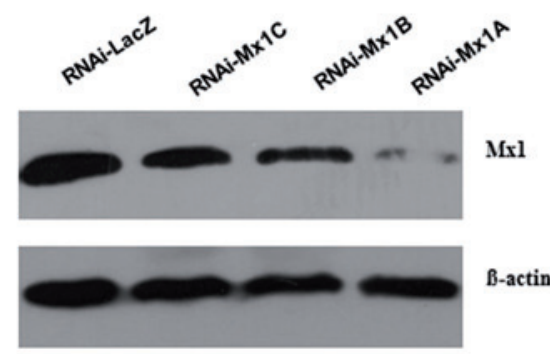

(b)

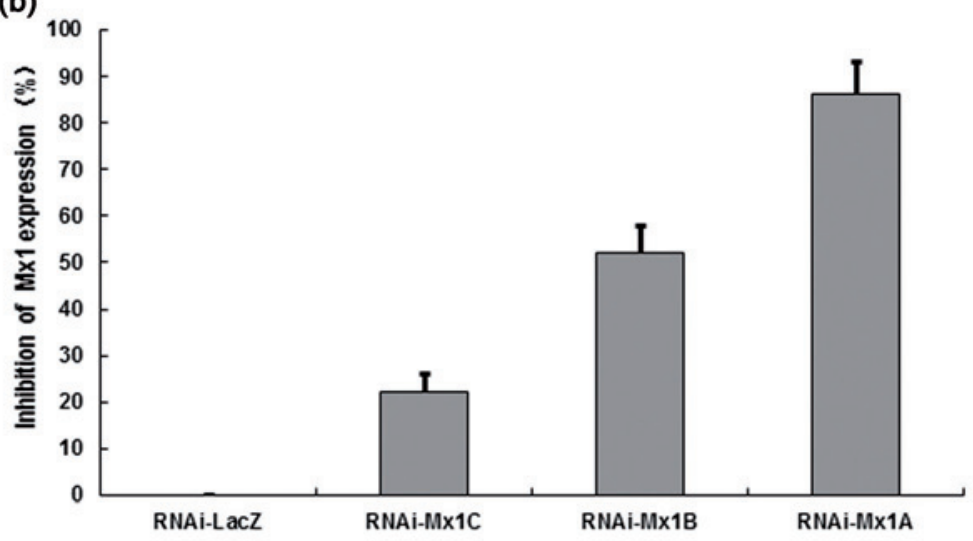

(c)

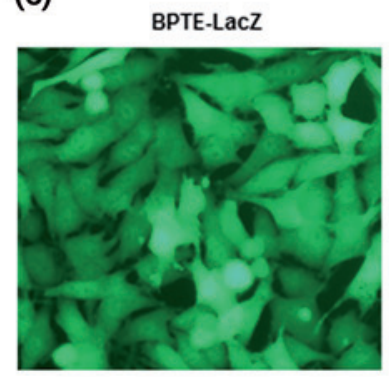

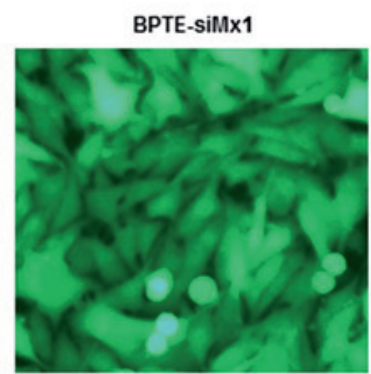

(d)

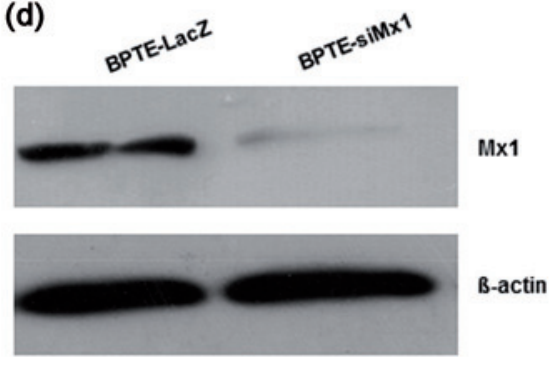

Fig. 1

Establishment of bovine fetal primary tracheal epithelial cell line silencing bovine Mxl

The shRNA vectors such as RNAi-LacZ, RNAi-Mx1-A, RNAi-Mx1-B, RNAi-Mx1-C, and pcDNA3.1-Flag-Mx1 were co-transfected into 293T cells, to select the shRNA vectors of best interfering efficiency with bovine Mx1 expression. Cell lysates of 293T cells co-transfected with relevant recombinant shRNA vectors and pcDNA3.1-Flag-Mx1 were separated by SDS-PAGE, and then analyzed for the expression of Flag-Mx1 by Western blot using antibodies against Flag and $\beta$-actin. The shRNAs against bovine Mxl significantly inhibited transient expression of Flag-Mxl as compared to the LacZ-control shRNA. The suppression effect on bovine Mxl expression was the highest with RNAi-Mxl-A (a). The results from three independent experiments in quadruplicate are presented as a percentage of mean transduction efficiency in treated cells \pm one SD (b). Vectors RNAi-Mx1-A and RNAi-LacZ were transfected into the bovine fetal primary tracheal epithelial cells. The shRNA recombinant lentivirus vector RNAi-Mx1-A and control vector RNAi-LacZ were transfected into the bovine fetal primary tracheal epithelial cells using Lipofectamine 2000. The Mx1-silencing cells BPTE-siMx1 and control cells BPTE-LacZ were screened by FACS, all of them expressed GFP (c), the expression of bovine Mx1 was indentified by Western blot (d). 
(Fig. 1a,b). RNAi-Mx1-A exhibited most pronounced effect on bovine Mxl expression. The results strongly suggested a direct role of shRNAs in specifically blocking transient expression of bovine Mx1 proteins in 293T cells.

Next, vector RNAi-Mx1-A was transfected into the bovine fetal primary tracheal epithelial cells. All bovine fetal primary tracheal epithelial cells expressed eGFP (encoded by recombinant $\mathrm{H} 1$ lentivirus) when screened by fluorescence activated cell sorting (FACS) (Fig. 1c), and the expression was confirmed by Western blot (Fig. 1d). The stable cell line of the primary bovine fetal tracheal epithelial cells with silenced expression of Mx1 was named BPTE-siMx1, and the control cell line was named BPTE-LacZ.
Bovine Mx1 silencing could promote the replication FMDV in primary bovine fetal tracheal epithelial cells

The primary bovine fetal tracheal epithelial cells induction solution containing $1 \times 10^{0}$ to $1 \times 10^{5} \mathrm{IU} / \mathrm{ml}$ of IFN- $\alpha$ was used to induce the primary bovine fetal tracheal epithelial cells, and the results showed that the optimal induction dose of IFN- $\alpha$ was $1 \times 10^{4} \mathrm{IU} / \mathrm{ml}$ (Fig. $2 \mathrm{a}$ ), the optimal induction time was $6 \mathrm{hr}$ (Fig. 2b). These conditions led to the induction of the highest expression level of bovine Mx1.

To understand the dynamics of FMDV replication in bovine Mx1-silencing cells, the assay developed above was used to characterize the kinetics of viral replication in
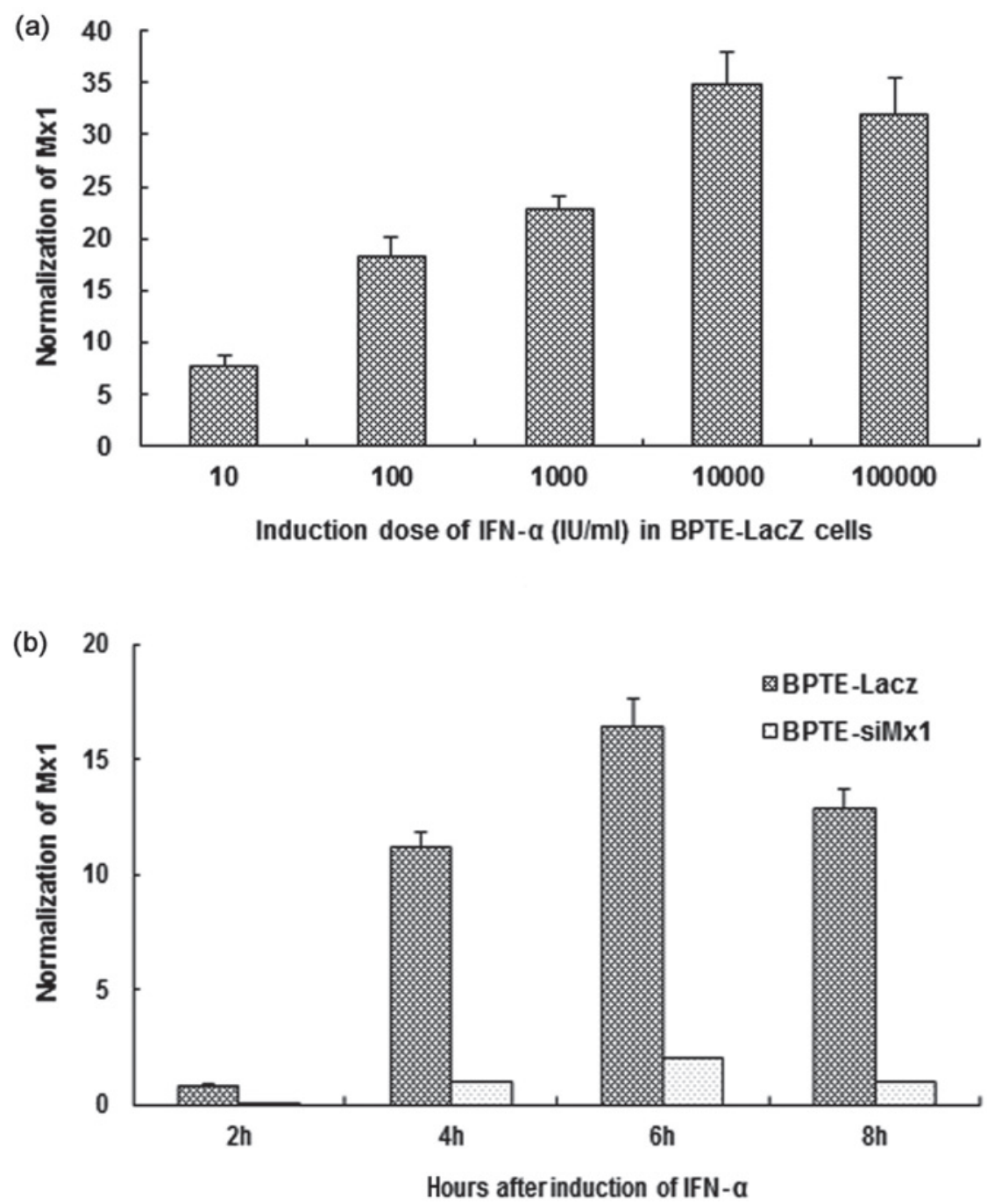

Fig. 2

The dose and time of $\alpha$-IFN that could induce the highest Mx1 gene expression

BPTE-siMxl cells and control cells BPTE-LacZ were cultured in 24-well plates in four replicates. Then IFN- $\alpha$-inducing dose and time were determined. RNA was extracted from the cells, and mRNA of the Mxl gene was analyzed quantitatively. The ratio of the expression of $M x 1 / \beta$-actin in the $10^{\circ}$ group was considered as 1 , and then the optimal time was determined to be $6 \mathrm{hr}$ and the optimal dose $1 \times 10^{4} \mathrm{IU} / \mathrm{ml}(\mathrm{a}$ and b). 


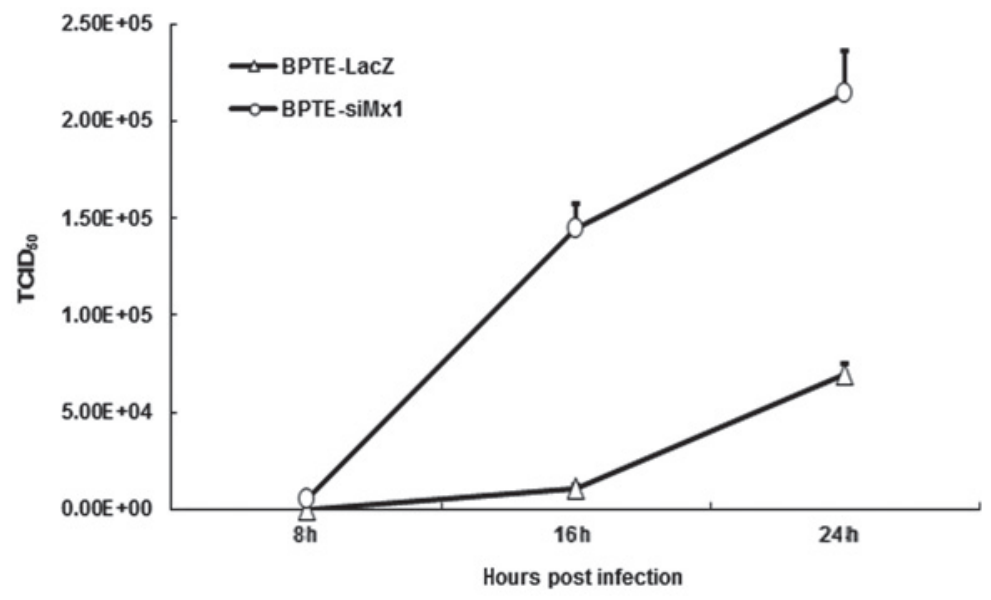

Fig. 3

Silencing bovine Mx1 could promote replication of FMDV in BPTE-siMx1 cells

The BPTE-siMxl and control cells BPTE-LacZ were cultured in 24-well plates. After induction with $1 \times 10^{4} \mathrm{IU}$ of IFN- $\alpha$ for 6 hr, each well was inoculated with the FMDV strain ASIA1/YS/CHA/05 at 1000 TCID $_{50}$. Every $8 \mathrm{hr}$ after FMDV inoculation, the cells and virus were collected, and viral replication was determined by $\mathrm{TCID}_{50}$. The graph shows the average $\mathrm{TCID}_{50}$ from three independent experiments in quadruplicate in treated cells and that in LacZ shRNA-expressing control cells \pm one standard deviation.

(a)

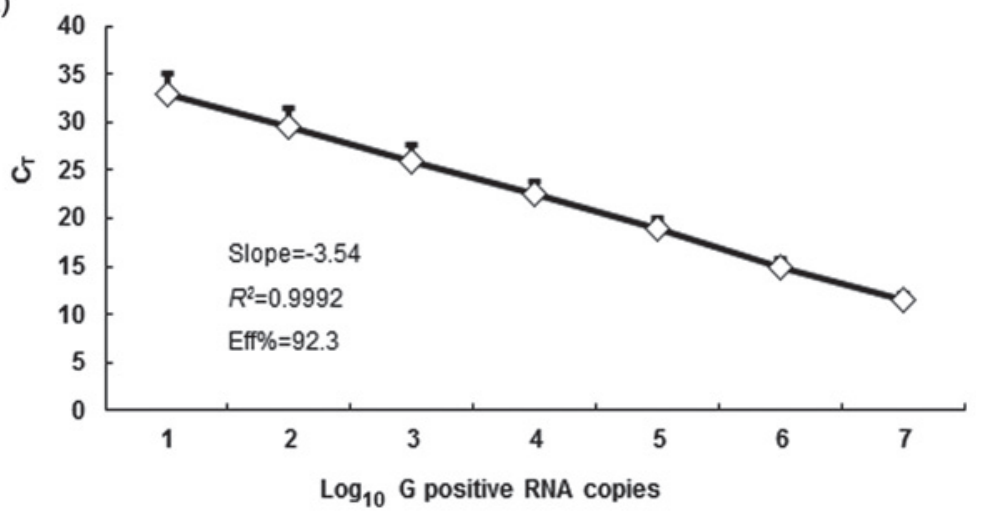

(b)

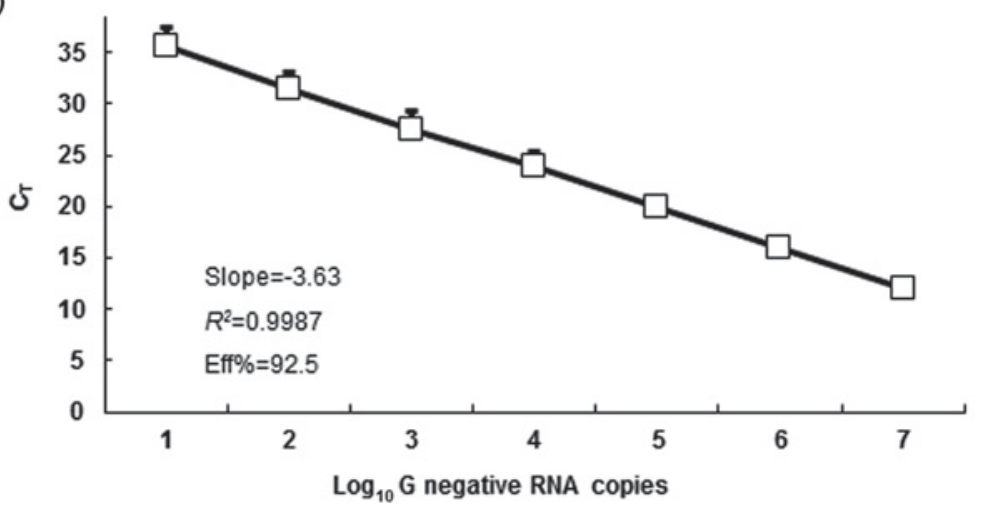

Fig. 4

Strand-specific RT-qPCR of FMDV genomic RNA

The standard curves were generated by quantifying in vitro transcribed RNA using the strand-specific RT-qPCR as described in the text. cDNAs synthesized by reverse transcription of either positive (a) or negative (b) strand using tagged RT primer were quantified using RT-qPCR. The experiment was performed in triplicate and mean Ct value with standard deviation was plotted against absolute RNA copy number. The correlation coefficients of the RT-qPCR are presented in the Table below each curve. 
FMDV-infected BPTE-siMxl cells. After IFN- $\alpha$ induction, BPTE-siMx1 and BPTE-LacZ cells were inoculated with FMDV at the dose of 1000 TCID $_{50}$ per well, and the viral titer was determined. The titer of the FMDV recovered from BPTE-siMX1 cells was 17-, 13- and 3-fold higher than the virus titer recovered from BPTE-LacZ cells at 8, 16 and $24 \mathrm{hr}$ post infection, respectively (Fig. 3). Thus, silencing of bovine Mx1 could increase the replication of FMDV in vitro.

Establishment of the standard curves of the positive- and negative-strand RNA of FMDV with strand-specific realtime fluorescence quantitative RT-PCR (ssqRT-PCR)

Standard RNA representing 1003 bp of the positive and negative strand of genomic RNA were synthesized by in vitro transcription as described in the Materials and Methods section. No amplification product was detected in control RNA from BPTE-LacZ cells. To determine the sensitivity of the strand-specific assays, cDNA reactions were diluted ten fold to eliminate any inhibitory effect of the components of the cDNA synthesis reaction. Two $\mu \mathrm{l}$ of the serially diluted cDNA of the standard RNA reactions was used in the qPCR reaction to generate standard curves for both positive and negative strand of the viral genomic RNA (Fig. 4). The minimum amount of standard RNA in this assay was 10 copies.

Silencing of Mx1 gene could promote the synthesis of the negative-strand RNA of FMDV

To understand the dynamics of viral RNA synthesis during FMDV replication in BPTE-siMx1 cell line, BPTE-siMx1 and BPTE-LacZ cells were infected with FMDV and harvested at $8 \mathrm{hr}, 16 \mathrm{hr}$ and $24 \mathrm{hr}$ post infection. Total RNA was extracted from the infected cells and subjected to the strand-specific RT-qPCR as described above. The copy numbers of the negative-strand RNA in BPTE-siMx1 cells were 24-, 32- and 14-fold higher than in BPTE-LacZ cells at $8 \mathrm{hr}, 16 \mathrm{hr}$ and $24 \mathrm{hr}$ post infection, respectively (Fig. 5a). The copy number of the (a)

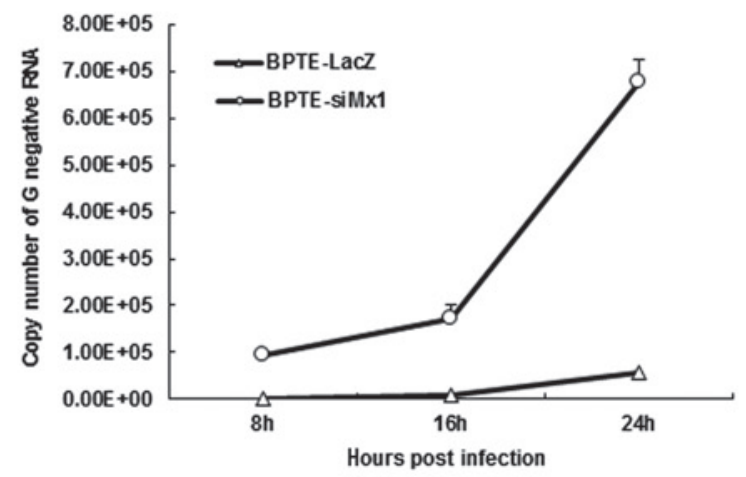

(c)

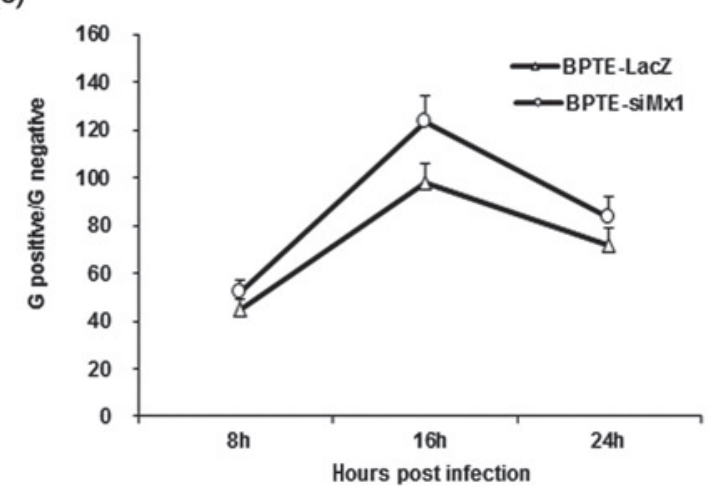

(b)

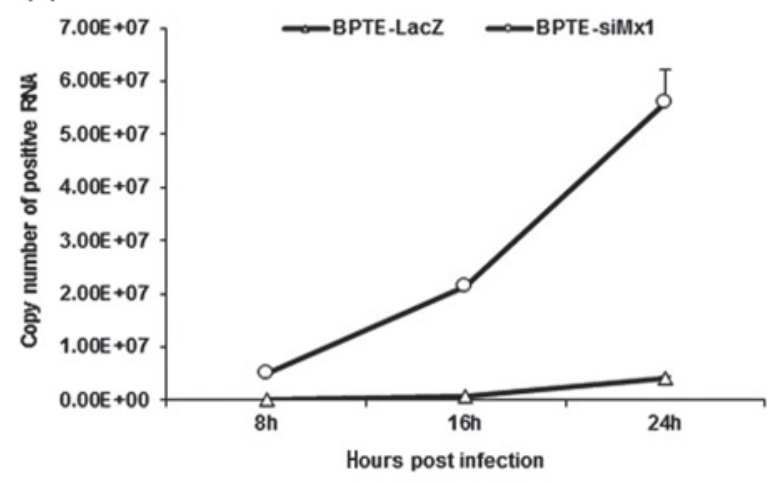

Fig. 5

Silencing of bovine Mxl could increase the replication of positive and negative strand of FMDV genomic RNA

BPTE-siMx1 cells and control cells BPTE-LacZ were cultured in 24-well plates, infected with FMDV at the dose 1000 TCID $_{50}$ per well and samples for RNA isolation were harvested in triplicate at stated time points post infection. The production of positive and negative strand viral RNA were plotted against time-points post infection ( $a$ and $b$ ). The ratio of positive and negative strands was calculated during the course of infection (c). Three experiments were repeated independently. 
positive-strand RNA in the infected BPTE-siMx1 cells were 29-, 47- and 14-fold higher than in the control cells at $8 \mathrm{hr}, 16$ $\mathrm{hr}$ and $24 \mathrm{hr}$ post infection, respectively (Fig. 5b).

Prior to $8 \mathrm{hr}$ post infection, the quantity of positiveand negative-strand RNA increased steadily. After $16 \mathrm{hr}$ post infection, the positive- and negative-strand increased rapidly, but the synthesis efficiency of positive strand was higher than that of negative strand. The ratio of positive- to negative-strand RNA was found to vary over the viral life cycle (Fig. 5c). The ratio increased initially, subsequently decreased after $16 \mathrm{hr}$, followed by a subsequent reduction in the later stages of the viral life cycle.

\section{Discussion}

Mammals, birds, fish, and invertebrates present a variable number of Mx protein forms, which can be localized in the cytoplasm or in the nucleus (Haller and Kochs, 2011). The Mx proteins have anti-viral activity against RNA viruses such as the influenza virus, the Thogoto virus, and coxsakievirus (Dotzauer and Kraemer, 2012; Matzinger et al., 2013; Patzina et al., 2014), and DNA viruses such as the hepatitis B virus and the African swine fever virus (Netherton et al., 2009; Li et al., 2012). The bovine Mx1 has also antiviral activity against the vesicular stomatitis virus, human rabies virus and murine respiratory syncytial virus (Baise et al., 2004; Leroy et al., 2006; Garigliany et al., 2009; Dermine and Desmecht, 2012). Although overexpression of bovine Mxl protein inhibited replication of FMDV in BHK-21 cells (Cai et al., 2013), its function needs to be further confirmed in naturally susceptible bovine cells from cattle, i.e. under normal physiological conditions.

In the present study, in the primary bovine fetal tracheal epithelial cell line BPTE-siMx1, in which the Mx1 gene was silenced with shRNA, the cytopathic effect appeared 8 hours earlier than in the control cell line BPTE-LacZ after induction of $a$-IFN followed by infection with FMDV. The viral titer $\left(\mathrm{TCID}_{50}\right)$ of the infected BPTE-siMx1 cell culture was 17-, 13-, and 3-fold higher than in the BPTE-LacZ cells at $8 \mathrm{hr}, 16 \mathrm{hr}$ and $24 \mathrm{hr}$ post infection, respectively. These findings further confirmed that bovine Mxl has anti-FMDVeffects.

Continuous expression of Mxl decreased the amount of the transcripts of influenza virus polymerase (Cilloniz et al., 2012), and overexpression of bovine Mx1 gene suppressed the synthesis of VP1 protein of FMDV (Cai et al., 2013). After an $8 \mathrm{hr}$ infection with influenza virus, the Vero cells stably expressing human MxA were found to have significantly lower copy numbers of positive-strand and negative-strand viral RNA as compared to the control cells (Xiao et al., 2013). In our study, the amount of positivestrand and negative-strand RNA of FMDV significantly increased in BPTE-siMx1 cells (silencing bovine Mx1) as compared to the control cells.
Since FMDV is a positive-strand RNA virus, the detection of positive-strand viral RNA did not necessarily mean that the virus replicates in tissues or cell. The first step of the viral replication is to start synthesis of the negative-strand RNA, and the synthesized negative-strand RNA is used as the template to synthesize the positive-strand RNA, which is further packaged into virions or used as the template for the synthesis of viral protein, and guides the synthesis of the viral protein in a cap structure-independent translation mode. The synthesis of the negative-strand RNA results in double-stranded RNA molecule, namely the replicative form RNA (RF-RNA) (Fry et al., 2005). The negative-strand RNA could reflect the replication level of the positive-strand RNA as a replicative intermediate, so the appearance of negative-strand RNA of FMDV is a hallmark of virus replication (Gu et al., 2007). In this study, the replication level of negative-strand viral RNA was 24-, 32- and 14-fold higher in Mx1-silencing BEPT-siMx1 cells than BEPT-LacZ cells at $8 \mathrm{hr}, 16 \mathrm{hr}$ and $24 \mathrm{hr}$ post infection, respectively. These findings implied that bovine $\mathrm{Mx} 1$ reduced the synthesis of viral positive- and negative-strand RNA, and thus inhibited replication of FMDV.

Acknowledgements. This work was supported by grants from the earmarked fund for the China Agriculture Research System (CARs-37 to HH), the National Natural Science Fund of China (31272586), the Shandong Agricultural Significant Application and Technological Innovation Fund (ZJF), the State Key Laboratory of Veterinary Biotechnology (SKLVBF201510), and the Open Subjects for the Major Basic Research Program of Science and Technology Department of Inner Mongolia Autonomous Region (HH).

\section{References}

Baise E, Pire G, Leroy M, Gérardin J, Goris N, De Clercq K, Kerkhofs P, Desmecht D (2004): Conditional expression of type I interferon-induced bovine Mx1 GTPase in a stable transgenic vero cell line interferes with replication of vesicular stomatitis virus. J. Interferon Cytokine Res. 24, 513-521. http://dx.doi.org/10.1089/jir.2004.24.513

Belsham GJ (2005): Translation and replication of FMDV RNA. Curr. Top. Microbiol. Immunol. 288, 43-70. http://dx.doi org/10.1007/3-540-27109-0 3

Cai KJ, Meng QL, Qiao J, Huang J, Zhang ZC, Wang GC, Wang JW, Chen CF (2013): Expression of bovine Mx1 protein inhibits the replication of foot-and-mouth disease virus in BHK-21 cells. Acta Virol. 57, 429-434. http://dx.doi. org/10.4149/av $2013 \quad 04 \quad 429$

Cilloniz C, Pantin-Jackwood MJ, Ni C, Carter VS, Korth MJ, Swayne DE, Tumpey TM, Katze MG (2012): Molecular signatures associated with Mx1-mediated resistance to highly pathogenic influenza virus infection: mechanisms of survival. J. Virol. 86, 2437-2446. http://dx.doi. org/10.1128/JVI.06156-11

Dermine M, Desmecht D (2012): In Vivo modulation of the innate response to pneumovirus by type-I and -III interferon- 
induced Bos taurus Mx1. J. Interferon Cytokine Res. 32, 332-337. http://dx.doi.org/10.1089/jir.2011.0123

Dias CC, Moraes MP, Weiss M, Diaz-San SF, Perez ME, Salazar AM, Santos T, Grubman MJ (2012): Novel antiviral therapeutics to control foot-and-mouth disease. J. Interferon Cytokine Res. 32, 462-473. http://dx.doi.org/10.1089/jir.2012.0012

Domingo E, Escarmis C, Baranowski E, Ruiz-Jarabo CM, Carrillo E, Nú-ez JI, Sobrino F (2003): Evolution of foot-andmouth disease virus. Virus Res. 91, 47-63. http://dx.doi. org/10.1016/S0168-1702(02)00259-9

Dotzauer A, Kraemer L (2012): Innate and adaptive immune responses against picornaviruses and their counteractions: An overview. World J. Virol. 1, 91-107. http://dx.doi. org/10.5501/wjv.v1.i3.91

Fernández-Trujillo MA, García-Rosado E, Alonso MC, Castro D, Álvarez MC, Béjar J (2013): Mx1, Mx2 and Mx3 proteins from the gilthead seabream (Sparus aurata) show in vitro antiviral activity against RNA and DNA viruses. Mol. Immunol. 56, 630-636. http://dx.doi.org/10.1016/j. molimm.2013.06.018

Fry EE, Stuart DI, Rowlands DJ (2005): The structure of foot-andmouth disease virus. Curr. Top. Microbiol. Immunol. 288, 71-101. http://dx.doi.org/10.1007/3-540-27109-0_4

Garigliany MM, Cloquette K, Leroy M, Decreux A, Goris N, De Clercq K, Desmecht DL (2009): Modulating mouse innate immunity to RNA viruses by expressing the Bos taurus Mx system. Transgenic Res. 18, 719-732. http://dx.doi. org/10.1007/s11248-009-9268-X

Gu C, Zheng C, Shi L, Zhang Q, Li Y, Lu B, Xiong Y, Qu S, Shao J, Chang H (2007): Positive and negative-stranded foot-andmouth disease virus RNA quantified simultaneously using a novel real-time RT-PCR. Virus Genes 34, 289-298. http://dx.doi.org/10.1007/s11262-006-0019-2

Haller O, Kochs G (2011): Human MxA protein: an interferoninduced dynamin-like GTPase with broad antiviral activity. J. Interferon Cytokine Res. 31, 79-87. http://dx.doi. org/10.1089/jir.2010.0076

Hauser MJ1, Dlugolenski D, Culhane MR, Wentworth DE, Tompkins SM, Tripp RA (2013): Antiviral responses by Swine primary bronchoepithelial cells are limited compared to human bronchoepithelial cells following influenza virus infection. PLoS One 8, e70251. http://dx.doi.org/10.1371/ journal.pone.0070251

He H, Sun Y (2007): Ribosomal protein S27L is a direct p53 target that regulates apoptosis. Oncogene 26, 2707-2716. http:// dx.doi.org/10.1038/sj.onc.1210073

He DN, Zhang XM, Liu K, Pang R, Zhao J, Zhou B, Chen PY (2014): In vitro inhibition of the replication of classical swine fever virus by porcine Mx1 protein. Antiviral Res. 104, 128-135. http://dx.doi.org/10.1016/j.antiviral.2014.01.020

Hoenen A, Gillespie L, Morgan G, vander Heide P, Khromykh A, Mackenzie J (2014): The West Nile virus assembly process evades the conserved antiviral mechanism of the interferon-induced MxA protein. Virology 448, 104-116. http://dx.doi.org/10.1016/j.virol.2013.10.005

Jamal SM, Belsham GJ (2013): Foot-and-mouth disease: past, present and future. Vet. Res. 44, 116. http://dx.doi. org/10.1186/1297-9716-44-116
Leforban Y (1999): Prevention measures against foot-and-mouth disease in Europe in recent years. Vaccine 17, 1755-1759. http://dx.doi.org/10.1016/S0264-410X(98)00445-9

Leroy M, Pire G, Baise E, Desmecht D (2006): Expression of the interferon-alpha/ beta-inducible bovine Mx1 dynamin interferes with replication of rabies virus. Neurobiol. Dis. 21, 515-521. http://dx.doi.org/10.1016/j.nbd.2005.08.015

Li N, Zhang L, Chen L, Feng W, Xu Y, Chen F, Liu X, Chen Z, Liu W (2012): MxA inhibits hepatitis B virus replication by interaction with hepatitis B core antigen. Hepatology 56 , 803-811. http://dx.doi.org/10.1002/hep.25608

Matzinger SR, Carroll TD, Dutra JC, Ma ZM, Miller CJ (2013): Myxovirus resistance gene A (MxA) expression suppresses influenza A virus replication in alpha interferontreated primate cells. J. Virol. 87, 1150-1158. http://dx.doi. org/10.1128/JVI.02271-12

Mitchell PS, Emerman M, Malik HS (2013): An evolutionary perspective on the broad antiviral specificity of MxA. Curr. Opin. Microbiol. 16, 493-499. http://dx.doi.org/10.1016/j. mib.2013.04.005

Netherton CL, Simpson J, Haller O, Wileman TE, Takamatsu $\mathrm{HH}$, Monaghan P, Taylor G (2009): Inhibition of a large double-stranded DNA virus by MxA protein. J. Virol. 83, 2310-2320. http://dx.doi.org/10.1128/JVI.00781-08

Patzina C, Haller O, Kochs G (2013): Structural Requirements for the Antiviral Activity of the Human MxA Protein Against Thogoto and Influenza A Virus. J. Biol. Chem. 289, 60206027. http://dx.doi.org/10.1074/jbc.M113.543892

Reed LJ, Muench H (1938): A simple method of estimating fifty percent endpoints. Am. J. Hyg. 27, 493-497.

Song MS, Cho YH, Park SJ, Pascua PN, Baek YH, Kwon HI, Lee OJ, Kong BW, Kim H, Shin EC, Kim CJ, Choi YK (2013): Early regulation of viral infection reduces inflammation and rescues mx-positive mice from lethal avian influenza infection. Am. J. Pathol. 182, 1308-1321. http://dx.doi. org/10.1016/j.ajpath.2012.12.022

Stertz S, Dittmann J, Blanco JC, Pletneva LM, Haller O, Kochs G (2007): The antiviral potential of interferon-induced cotton rat Mx proteins against orthomyxovirus (influenza), rhabdovirus, and bunyavirus. J. Interferon Cytokine Res. 27, 847-855. http://dx.doi.org/10.1089/jir.2006.0176

Vashist S, Urena L, Goodfellow I (2012): Development of strand specific real-time RT-qPCR assay for the detection and quantitation of murine norovirus RNA. J. Virol. Methods 184, 69-76. http://dx.doi.org/10.1016/j.jviromet.2012.05.012

Verhelst J, Hulpiau P, Saelens X (2013): Mx proteins: antiviral gatekeepers that restrain the uninvited. Microbiol. Mol. Biol. Rev. 77, 551-566. http://dx.doi.org/10.1128/MMBR.00024-13

Wang HM, Wu JM, Liu X, He HB, Ding FR, Yang HJ, Cheng L, Liu W, Zhong JF, Dai YP, Li GP, He CQ, Yu L, Li J (2012): Identification of short hairpin RNA targeting foot-and-mouth disease virus with transgenic bovine fetal epithelium cells. PLoS One 7, e42356. http://dx.doi.org/10.1371/journal.pone.0042356

Xiao H, Killip MJ, Staeheli P, Randall RE, Jackson D (2013): The human interferon-induced MxA protein inhibits early stages of influenza A virus infection by retaining the incoming viral genome in the cytoplasm. J. Virol. 87, 13053-13058. http://dx.doi.org/10.1128/JVI.02220-13 